\title{
Doğu Akdeniz'de Yayılış Gösteren Microtus subterraneus Kısakulaklı Farenin (Rodentia: Cricetidae)'nin Ekolojik Tercihleri
}

\author{
Mustafa Yavuz \\ Akdeniz Üniversitesi, Fen Fakültesi, Biyoloji Bölümü, Antalya, Türkiye, (ORCID: 0000-0002-2104-741X), myavuz.akd@gmail.com
}

(İlk Geliş Tarihi Aralık 2020 ve Kabul Tarihi Ocak 2021)

(DOI: $10.31590 /$ ejosat.846971)

\begin{abstract}
ATIF/REFERENCE: Yavuz, M., (2021). Doğu Akdeniz'de Yayılış Gösteren Microtus subterraneus Kısakulaklı Farenin (Rodentia:
\end{abstract} Cricetidae)'nin Ekolojik Tercihleri. Avrupa Bilim ve Teknoloji Dergisi, (22), 65-70.

$\ddot{\mathbf{O z}}$

Bu çalışmada 2009-2010 yıllarında Doğu Akdeniz Bölgesi'nde yaşayan M. subterraneus popülasyonlarının tercih ettiği habitatın

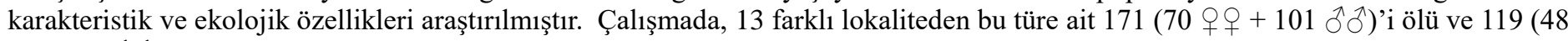
ㅇ++71 $\widehat{\partial}$ ) canlı olmak üzere toplam 290 örnek yakalanmıştır. Analizler neticesinde örneklerin ölü ve canlı olarak yakalanma frekansları bakımından eşeyler arasında istatistiksel olarak anlamlı farklılıklar bulunmuştur $\left(\chi^{2}\right.$ ölü $=17.79, \mathrm{df}=1, \mathrm{p}=0.001$ ve $\chi^{2}$ canlı $=$ $15.83, \mathrm{df}=1, \mathrm{p}=0.001)$. Erkek örnekler dişi bireylere oranla daha çok yakalanmışlardır. Tür mesik karakterli habitatları tercih etmesine rağmen bu tip formasyonlara komşu karışık habitatlarda da bulundukları görülmüştür. Yakalanan ölü örneklerin 142 (\% 83.04$)$ 'si, canlı örneklerin ise 85 (\% 71.43)'i 31-60\% 'lik eğimli alanlardan yakalanmıştır. Bu eğim aralığında populasyon yoğunlukları da en yüksek seviyede bulunmuştur. Ayrıca türün yakın akraba türler gibi yuvalarını çoğunlukla güneş alan bakılara yaptı̆̆ı, güneş alan yönlerin daha fazla oranda tercih edildiği görülmüştür. Ölü olarak yakalanan örneklerin 129 (\% 75.44)'unun ve canlı yakalanan örneklerin 111 (\% 93.28)'inin, populasyon yoğunluğunun ise 508 (\% 83.83)'inin güney, güneydoğu ve güneybatı yönünde olduğu görülmüştür. Bu çalışma bu bölge için bu kapsamdaki ilk kayıtları oluşturmaktadır.

\section{Ecological Preferences of the European Pine Vole Microtus subterraneus (Rodentia: Cricetidae), Distribute in the Eastern Mediterranean Region}

\begin{abstract}
In this study, were investigated the characteristic and ecological features of the habitat preferred by M. subterraneus populations living in the Eastern Mediterranean Region between 2009-2010. In the study, a total of 290 specimens, $171\left(+\circ 70+\lambda \sigma^{\lambda} 101\right)$ of this species were caught dead and $119(+q 48+\delta \delta 71)$ alive from 13 different localities at the region. As a result of the analysis, statistically significant differences were found between the sexes in terms of the frequency of catching dead and alive samples $\left(\chi^{2}\right.$ dead $=17.79, \mathrm{df}=1, \mathrm{p}=0.001$ ve $\chi^{2}$ alive $\left.=15.83, \mathrm{df}=1, \mathrm{p}=0.001\right)$. Male specimens were caught more than females. Although the species prefers habitats with mesic character, it has been observed that they are also found in mixed habitats adjacent to this type of formations. $142(83.04 \%)$ of the dead specimens and $85(71.43 \%)$ of the alive specimens were caught from the areas with slopes of $31-60^{\circ}$. Population densities were also at the highest level in this slope range. In addition, it has been observed that the species, like closely related species, make their nests mostly in the sun-exposed areas, and the sunny directions are more preferred. It was observed that, $129(75.44 \%)$ of the samples which was caught dead and $111(93.28 \%)$ of the samples caught alive, and the population density of $508(83.83 \%)$ were in the south, southeast and southwest direction. This study constitutes the first records in this scope for this region.
\end{abstract}

Keywords: Microtus subterraneus, Rodentia, Eastern Mediterranean, slope, direction, temperature 


\section{Giriş}

Hayvanların ekolojik istek ve tercihlerinin bilinmesi onların nişlerinin daha iyi anlaşılmasının yanında, ilişkili türlerin durumlarının daha iyi anlaşılmasında önemli rol oynar. Akadeniz Bölgesi dikkate alındığında; Microtus subterraneus (SelysLongchamps, 1836) türünün çayırlarda, bahçelik alanlarda ve tarım alanlarına yakın yerlerde yayılış gösterdiği bilinmektedir (Kryštufek ve Vohralik, 2005). Yeraltında görece sı̆̆ yuvalarda (30-40 cm derinliklerde) kazdıkları tünellerde koloniler halinde yaşamaları, böylece kış şartlarına ve kuraklık gibi ekstrem durumlara dayanıklı olmaları nedeniyle Cricetidae ailesi içerisinde dikkat çekmektedirler. Tarım alanlarına yakın yaşamaları ve herbivor beslenme tercihleri nedeniyle potansiyel olarak tarım zararlısı olabilirler. Tarım ürünleri üzerinde etkili olmaları nedeniyle ekonomiye etkileri de söz konusudur. Ülkemiz gibi tarımın önemli bir ekonomik kaynak olduğu yerlerde etkili tarım politikalarının ve stratejilerinin geliştirilmesinde bu türlerin ekolojik tercihlerinin bilinmesi hayati önem taşımaktadır. Günümüzde; zararlılarla mücadelede verilen zararın bilinmesinden çok, zararlının yaşam alanlarının, yaşam döngülerinin, ekolojik ve etholojik özelliklerinin bilinmesinin daha önemli olduğu anlaşılmıştır.

$\mathrm{Bu}$ kapsamda türün yakın akrabalarından Microtus guentheri, Microtus levis ve Microtus anatolicus gibi türlerin ekolojik tercihleriyle ilgili çalışmalar (Yavuz ve ark., 2010, 2011a ve b, Yavuz ve Tunç, 2016) bulunmasına rağmen, $M$. subterraneus ile ilgili çalışmalar (Çolak ve ark. 1998) oldukça sınırlıdır. Bu çalışmalar incelendiğinde; türün ekolojisiyle ilgili detaylı verilere rastlanılmamaktadır. Özellikle türün habitat eğimi, yuvaların yapıldığı habitatların yönleri (bakı), sıcaklık ilişkileri vb. ekolojik değişkenlerle ilgili veriler yer almamaktadır.

Bu çalışma ile türün ekolojik tercihlerinin, bölgede yaşadığı habitatların genel özelliklerinin, tercih ettiği eğim derecelerinin ve seçtiği yönlerin neler olduğu araştırılmıştır. $\mathrm{Bu}$ veriler çalışılan lokaliteler ve kapsamı itibariyle ilk kayıt olma niteliğindedir.

\section{Materyal ve Metot}

\subsection{Arazi Çalışmaları ve Uygulama Düzeni}

Bu çalışma Doğu Akdeniz Bölgesi'nde (Gazipaşa ilçe sınırı-Gaziantep il sınırı arasında kalan kısım) yayılış gösteren Microtus subterraneus türüne ait populasyonların yaşadığ habitatların bazı ekolojik ve biyotaksonomik özelliklerini araştırmak amacıyla, 2009-2010 yıllarında gerçekleştirilmiştir. Çalışmada incelenen 52 lokaliteden, sadece 13 farklı lokalitede M. subterraneus türüne ait $171(70$ 우 +101 ふ઼す)'i ölü ve 119

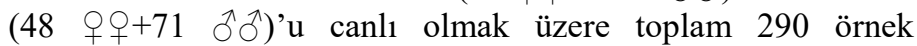
yakalanmıştır (Şekil 1).

Örneklerin yakalanması amaciyla sahada yapılan çalışmalarda her periyotta 100 adet yaylı ve 50 adet shermann tipi canlı örnek yakalama kapanları kullanılmıştır. Bu kapanlar arazinin eğimi (iki grup olarak ele alınmıştır: 0-45 ve 46-90) ve bakı durumları (Güney= Güney, Güneydoğu, Güneybatı ve Kuzey= Kuzey, Kuzeydoğu ve Kuzeybatı) dikkate alınarak her $10 \mathrm{~m}^{2}$ ye 1 kapan gelecek şekilde yerleştirilmiştir. Buna göre; yaylı kapanlardan 50 tanesi sahaya ulaşılan günün akşamı (güneş batmadan iki saat önce), diğer 50'si ertesi günün sabahı yerleştirilmiş ve akşam güneş batmadan 2 saat önce (yarım gün sonra) kontrol edilmiştir. Sharmann tipi kapanlar ise çalışma günün sabahı araziye yerleştirilip, ertesi günün sabahı (bir gün sonra) kontrol edilmişlerdir. Örnekleri kapanlara çekmek amacıyla kavrulmuş yer fistığıyla çiğnenerek hamur haline getirilmiş bir miktar buğday ekmeği kullanılmıştır (Yavuz ve ark., 2011a).

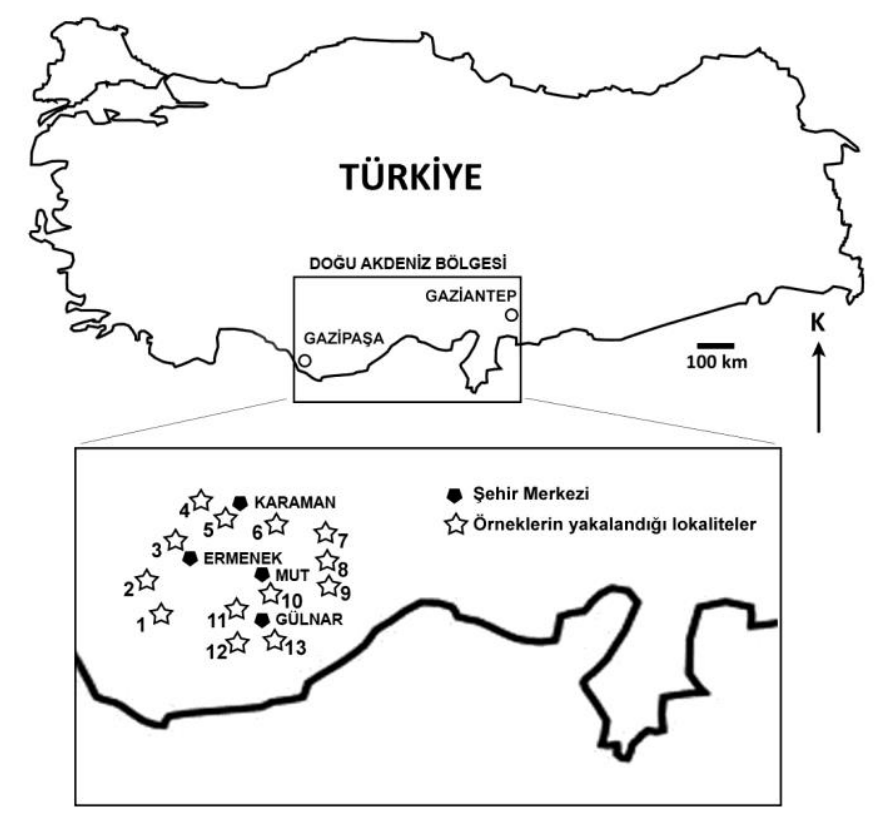

Şekil 1. Doğu Akdeniz Bölgesi'nde örneklerin yakalandığ lokaliteler

Çalışmada canlı yakalan örnekler populasyon yoğunluğu hesaplanmasında kullanılmışlardır. Bunun için, yakalanan örneklerin "Mark-Recapture Population Sampling Method of Lincoln-Peterson (Lincoln-Peterson'un işaretle-tekrar yakala populasyon örnekleme) metoduna göre sırt kılları boyanıp, yaklaşık $0,5 \mathrm{~cm}$ çapında bir daire şeklinde işaretlenerek serbest bırakılmışlardır. $\mathrm{Bu}$ uygulamada rastgele olarak yakalanan örneklerin tümünün sirt k1lları boyanarak serbest bırakılmaktadır". Sonraki periyotta yine rasgele örneklemeye uygun bir şekilde yakalanan tüm örneklerin kaç tanesinin işaretli olduğu tespit edilmektedir. En son olarak araştırılan her değişken için (bu çalışma için eğim ve bakı değişken olarak alınmıştır) ayrı ayrı belirlenen bu değerler aşağıdaki matematiksel eşitlikte yerlerine konulmakta ve istatistiksel analizlerde kullanılabilecek populasyon yoğunluğu verisi hesaplanmaktadır (Krebs, 1999; Pollock ve ark., 1990).

\section{$\mathbf{N}=\mathbf{M} . \mathbf{C} / \mathbf{R}$}

Burada,

$\mathbf{N}=$ Hesaplanan populasyon büyüklüğü

$\mathbf{M}=$ İlk uygulama sırasında işaretlenen birey sayısı

$\mathbf{C}=$ İkinci uygulama sirasında yakalanan toplam birey sayısı

$\mathbf{R}=$ İkinci uygulama sırasında yakalanan işaretli birey sayısını ifade etmektedir.

\section{2. İstatistiksel analiz}

Veriler SPSS 20.0, IBM paket programı kullanılarak değerlendirilmiştir. Gruplar yazım kolaylığı sağlanması ve karmaşıklığı azaltması amacıyla metin içerisinde ölü (yaylı kapana yakalanan örnekler için), canlı (sherman tuzaklarına 
yakalanan örnekler için) ve PY (populasyon yoğunluğu) olmak üzere adlandırılmışlardır. Populasyon dinamikleri, eğim, bakı ve sıcaklık değişimleri arasındaki ilişkilerin irdelenebilmesi için kolaylık sağlaması açısından; eğim değerleri $0-45$ ve $46-90^{\circ}$ olmak üzere, bakı durumları ise Güney= Güney, Güneydoğu, Güneybatı ve Kuzey= Kuzey, Kuzeydoğu ve Kuzeybatı olmak üzere iki gruba ayrılmıştır. Her bir grup için veri dağılımlarının normal olup olmadığı Shapiro-Wilk Normal Dağılıma Uygunluk testi ile kontrol edilmiştir (Yavuz ve ark., 2010).

Sicaklık verilerinin diğer değişkenlerle (eğim ve bakı) olan ilişkisini araştırmak amacıyla farklı eğimlerdeki sahalarda yer alan rastgele seçilen galerilerin giriş ve/veya çıkış deliklerinin içerisine yaklaşı $15 \mathrm{~cm}$ derinliğe doğrudan dijital termometreler yerleştirilmiştir. Yerleştirilen bu dijital termometreler ile aynı gün öğle $12^{00}-13^{00}$ ile gece $23^{00}-24^{00}$ saatleri arasında sicaklık ölçümleri yapılmış ve kaydedilmiştir. Bunun yanında yuva deliklerine rastlanılmayan (81-90 lik eğimli yerler) sahalarda ise, toprak içine $15 \mathrm{~cm}$ derinliğe sokulan termometrelerle ölçüm yapılmıştır. Böylece elde edilen sıcaklık verileri üç ayrı grupta; gündüz, gece ve gündüz-gece farkı irdelenebilmiştir.

Türün ekolojisinin daha iyi anlaşılması ve varsa habitat tercihlerinin ortaya konulması, bu tercihlerin eğim değişkeniyle ilişkisinin araştırılmasında Pearson Korelasyonundan yararlanılmıştır. Ayrıca, her istatistiksel grup için ortalama yakalanma frekansları ve populasyon yoğunlukları bazında gruplar arasında fark olup olmadığı Student-t testinden yararlanılarak değerlendirilmiştir. Son olarak, bağımsız bir değişken olan sıcaklık verilerinin gruplar arasındaki farklılığının değerlendirilmesinde ise Tek Faktörlü Varyans Analizi (Oneway ANOVA) kullanılmıştır. Tüm istatistiksel analizlerde ve testlerde kabul edilebilir en yüksek yanılma payı $\mathrm{p}=0.05$ olarak alınmıştır. Ayrıca her test için geçerli olası güvenirlik düzeyi verilmiştir.

\section{Araştırma Sonuçları ve Tartışma}

\subsection{Eşey Dağılımı ve Populasyon Yoğunluğu}

Yapılan istatistiksel analizler sonucunda; eşeylerine göre örneklerin ölü ve canlı olarak yakalanma frekansları bakımından eşeyler arasında istatistiksel farklılık bulunmuştur (sırasıyla; $\chi^{2}$ ölü $=17.79, \mathrm{df}=1, \mathrm{p}=0.001$ ve $\chi^{2}$ canl $\left._{1}=15.83, \mathrm{df}=1, \mathrm{p}=0.001\right)$. Ölü örneklerin 123 (\% 71.93)'ü ergin, 48 (\% 28.07)'i genç bireylerden oluşurken, erginlerin 48 (\%39.02)' i dişi ve 75 (\%60.98)'i erkek, gençlerin ise 22 (\% 45.83)'si dişi ve 26 (\% 54.17)'sı erkektir. Yani erkek bireyler dişi bireylere oranla daha çok yakalanmışlardır.

Canlı yakalanan 119 örneğin sırt kılları boyanıp işaretlenmiş ve sonra serbest bırakılmışlardır. Bırakılan bu 119 örnekten sonra, 56 (\%47.06) örnek ise sonraki periyotta yakalanmıştır. Sonradan yakalanan örneklerin 11 tanesinin işaretli olduğu görülmüş olup, buna göre tür için PY (=populasyon büyüklüğü) yaklaşı 606 birey olarak hesaplanmıştır.

\subsection{Ekolojik Tercihleri}

\subsubsection{Habitatın Genel Özellikleri}

Çamlık Tarla Faresi öncelikli olarak mesik (verimsiz, kurak yada yarı kurak) karakterli habitatları tercih etmesine rağmen bu tip formasyonlara komşu karışık habitatlarda da bulunabilirler.
Yayılış alanları içinde Alnus sp., Platanus sp. ve yoğunlukla Quercus sp. türlerinden oluşan formasyonları görmek mümkündür. Daha yüksek rakımlar ve dağ eteklerinde çoğunlukla Pinus sp. Quercus sp. formasyonlarının olduğu habitatların kenarlarını tercih ederler. Yüksek ovalarda Rubus sp. gibi kurakçıl formlar ve konifer ormanlarının kenarlarında geniş yayılışları vardır (Kryštufek ve Vohralik, 2005). Türün yayılış alanında bulunan formasyonların sıklığı arttıkça PY düşmektedir.

Diğer taraftan, türün en yoğun olduğu alanların bu formasyon tiplerinin tarım alanlarıyla ve silvikültürel sahalarla kesiştiği dar zonlar olduğu görülmüştür. Yakalanan ölü örneklerin $124 \quad(\% 72.51)$ 'ü bu zonlardan yakalanmıştır. Buralarda yuvalanan populasyonun galerileri yakın formasyonların içine kadar uzanır. Oysa çayır-mera, yoğun taşlık-kayalık, yol kenarı vb habitat tiplerinde türün bireylerine rastlanmamıştır. Bulundukları habitatlarda formasyon sık değil ise; özellikle eğimli alanlarda yayılış gösterirlerken, formasyon sık ve 1şık geçirgenliği çok değilse, az da olsa düzlüklerde de rastlanmışlardır.

M. subterraneus türünün tercih ettiği habitatın genel görünümü aşağıda Şekil 2'de verilmiştir.

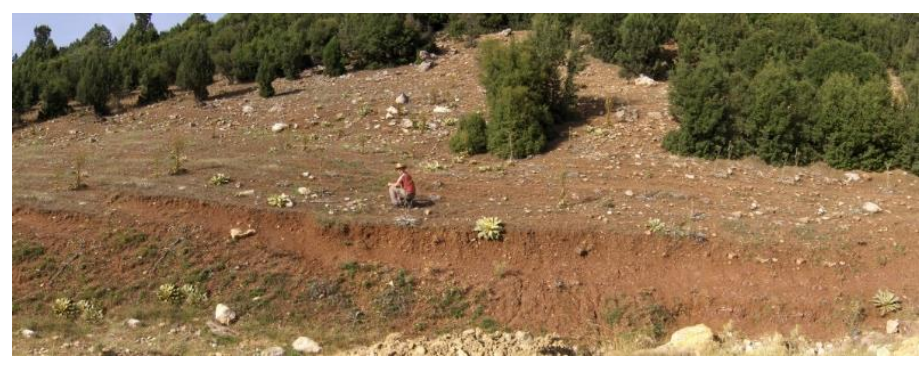

Şekil 2. M. subterraneus türünün tercih ettiği habitatın genel görünümü.

\subsubsection{Habitatın Ĕ̈imi}

Yakalanan ölü örneklerin 142 (\% 83.04) 'si, canlı örneklerin ise 85 (\% 71.43)'i 31-60 'lik eğimli alanlardan yakalanmıştır. Bu eğim aralığında PY en yükssek bulunmuştur (Şekil 3).

M. subterraneus populasyonları tarafindan yuva yapımı için tercih edilen araziye ait eğim dereceleri ile PY, ölü ve canlı yakalanma frekanslarının ilişkileri Şekil 3-5'te verilmiştir. Buna göre; 0-45'lik eğime sahip alanlarda ölü ve canlı örneklerin yakalanma frekansları, PY ve eğim arasında pozitif korelasyonlar olduğu saptanmıştır (sırasıyla, $r_{\text {ölü }}=0.843 ; n=9$; $\left.\mathrm{p}<0.001, \mathrm{r}_{\text {canl }}=0.631 ; \mathrm{n}=9 ; \mathrm{p}<0.001, \mathrm{r}_{\mathrm{py}}=0.880 ; \mathrm{n}=9 ; \mathrm{p}<0.0001\right)$. Diğer taraftan $46-90^{0}$ lik eğimli alanlarda ise bu faktörler bakımından negatif korelasyon olduğu (sırasıyla, $\mathrm{r}_{\text {ölü }}=-0.812$; $\mathrm{n}=9 ; \mathrm{p}<0.0001, \mathrm{r}_{\text {canl }}=-0.714 ; \mathrm{n}=9 ; \mathrm{p}<0.002, \mathrm{r}_{\mathrm{py}}=-0.955 ; \mathrm{n}=9$; $\mathrm{p}<0.0001$ ) bulunmuştur. Yani eğim $0-45^{0}$ arasında arttıkça habitatın tercih edilme oranının arttığ arttıkça habitatın tercih edilme oranının düştüğü gözlenmiştir.

Diğer taraftan, iki eğim grubu arasında ölü ve canlı

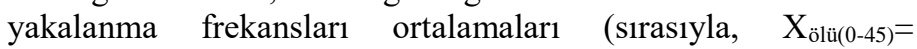
$\left.7.66 \pm 0.615,5.68 \pm 3.64 ; \mathrm{X}_{\text {canl1 }(46-90)}=6.61 \pm 2.123,4.37 \pm 2.300\right)$ 
bakımından istatistiksel önemde bir farklılık bulumamıştır ( $\mathrm{t}_{\text {ölü }}=0.25 ; \mathrm{df}=15 ; \mathrm{p}>0.793, \mathrm{t}_{\text {canl }}=0.118 ; \mathrm{df}=18 ; \mathrm{p}>0.944$ ).

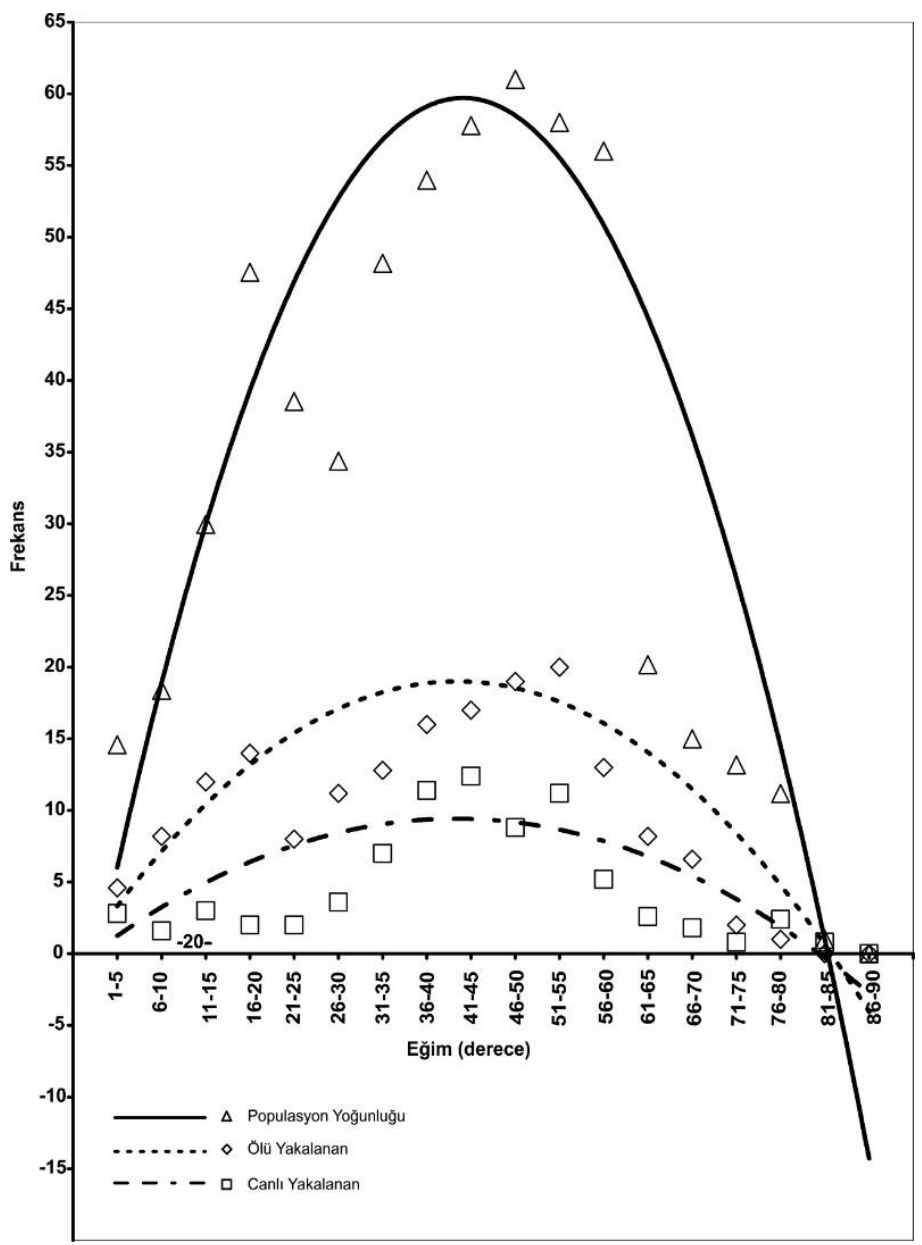

Şekil 3. M. subterraneus tarafından kullanılan habitatlar için 0$90^{0}$ 'lik eğim grubu ile PY, ölü ve canlı yakalanma frekansları arasındaki ilişki

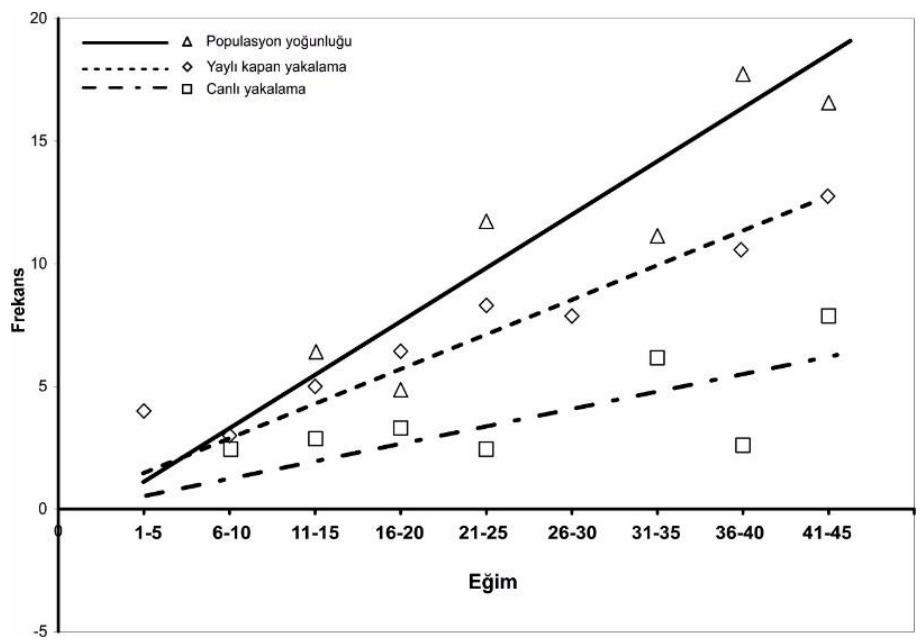

Şekil 4. M. subterraneus tarafından kullanılan habitatlar için 0$45^{\circ}$ 'lik eğim gurubu ile PY, ölü ve canlı yakalanma frekansları arasındaki ilişki

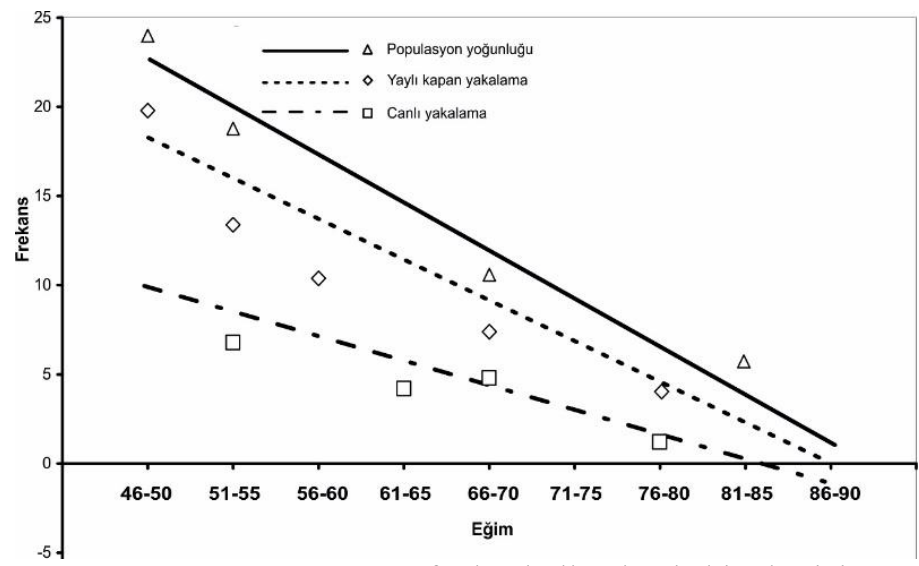

Şekil 5. M. subterraneus tarafindan kullanılan habitatlar için 46$90^{0}$ 'lik eğim gurubu ile PY, ölü ve canlı yakalanma frekansları arasındaki ilişki

\subsubsection{Bakı Tercihi ve Sıcaklık İlişkileri}

Sahalarda yapılan çalışmalarda türün yuvalarını çoğunlukla güneş alan bakılara yaptığı, güneş alan yönlerin daha fazla oranda tercih edildiği görülmüştür. $M$. subterraneus yuvaların bakıları incelendiğinde; ölü olarak yakalanan örneklerin $129(\%$ 75.44)'unun ve canlı yakalanan örneklerin 111 (\% 93.28)'inin, PY'nun ise 508 (\% 83.83)'inin güney, güneydoğu ve güneybatı yönünde olduğu görülmüştür (Şekil 6). Ayrıca örneklerin yaylı kapana ölü olarak yakalanma frekansları ortalamaları ve PY ortalamaları bakımından kuzey ve güney bakıları arasındaki farklar istatistiksel olarak anlamlıdır (sırasıyla, $\mathrm{t}_{\text {ölü }}=4.42 ; \mathrm{df}=8$; $\mathrm{p}<0.001$ ve $\left.\mathrm{t}_{\mathrm{py}}=3.65 ; \mathrm{df}=8 ; \mathrm{p}<0.001\right)$. Yine canlı yakalama frekansı bakımından kuzey bakılarından hiçbir örnek yakalanmamıştır.

Bakılara göre sıcaklık ilişkileri irdelendiğinde ise; Güney bakılar için $0-45^{\circ}$ 'lik eğim gurubunda eğim ile ortalama gündüz ve gece sıcaklıkları arasında çok güçlü pozitif bir korelasyon vardır (sırasiyla, $r_{\text {gündüz }}=0.921 ; \mathrm{p}<0.001, \mathrm{r}_{\text {gece }}=0.925 ; \mathrm{p}<0.0001$ ). Oysa aynı grupta eğim ile ortalama gündüz-gece farkı arasında çok güçlü negatif bir korelasyon bulunmuştur $\left(\mathrm{r}_{\text {fark }}=-0.912\right.$; $\mathrm{p}<0.001$ ). Diğer taraftan, $46-90^{\circ}$ 'lik eğim grubu için, eğim ile ortalama gündüz ve gece sıcaklıkları arasında çok güçlü negatif bir korelasyon vardır (sırasıyla, $r_{\text {gündüz }}=-0.888 ; \mathrm{p}<0.001, \mathrm{r}_{\text {gece }}=-$ $0.896 ; \mathrm{p}<0.01$ ). Oysa aynı grupta eğim ile ortalama gündüz-gece fark1 arasında güçlü pozitif bir korelasyon bulunmuştur $\left(\mathrm{r}_{\text {fark }}=0.845 ; \mathrm{p}<0.01\right)$.

Yine güney bakılar için; her iki eğim grubundan gündüz ve gece ölçülen ortalama sicaklıklar ile gündüz-gece fark1 ortalamaları arasındaki farklar önemli bulunmuştur $\left(F_{\text {gündüz }}=46.511 ; \mathrm{df}_{1}=8 ; \mathrm{df}_{2}=710 ; \mathrm{p}<0.0001, \mathrm{~F}_{\text {gece }}=75.001 ; \mathrm{df}_{1}=8\right.$; $\left.\mathrm{df}=710 ; \mathrm{p}<0.0001, \mathrm{~F}_{\text {fark }}=148.202 ; \mathrm{df}_{1}=8 ; \mathrm{df}=710 ; \mathrm{p}<0.0001\right)$. Aynı zamanda gündüz ve gece $0-45^{0}$ 'lik eğim grubundan ölçülen değerler ile $46-90^{\circ}$ lik eğim grubundan ölçülen değerler arasındaki fark anlamlıdır ( $\mathrm{t}_{\text {gündüz }}=12.223 ; \mathrm{df}=405 ; \mathrm{p}<0.001$, $\left.\mathrm{t}_{\text {gece }}=9.116 ; \mathrm{df}=405 ; \mathrm{p}<0.001, \mathrm{t}_{\text {fark }}=10.508 ; \mathrm{df}=405 ; \mathrm{p}<0.001\right)$. 


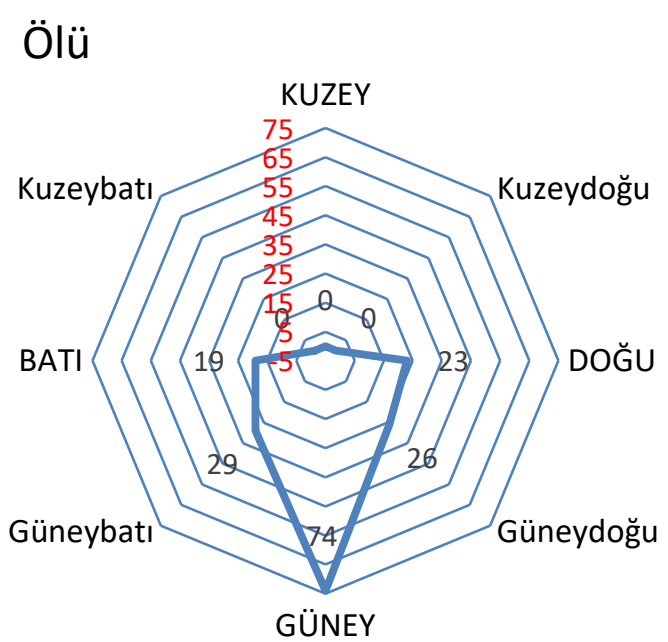

Canlı

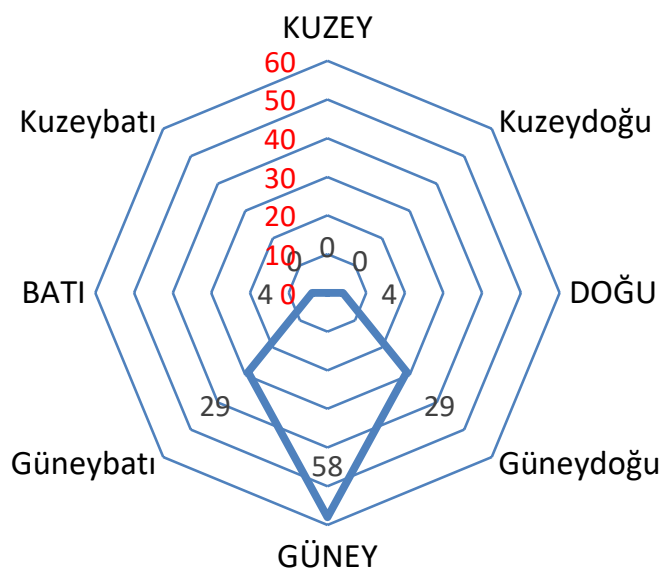

Populasyon Yoğunluğu (PY)

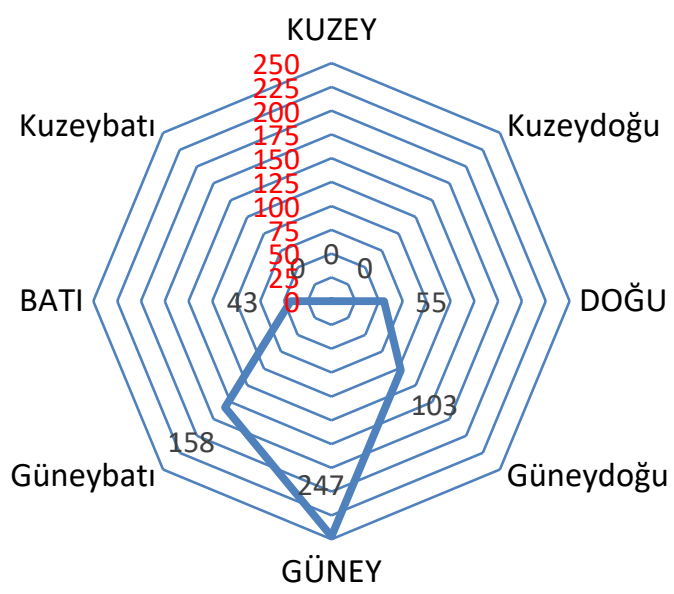

Şekil 6. M. subterraneus bireylerinin yaşadığı habitatların bakıları (yönleri) ile ölü ve canlı yakalanma frekansları yanında PY arasındaki ilişki
Kuzey bakılar için ise; $0-45^{0}$ 'lik eğim grubunda eğim ile ortalama gündüz ve gece sıcaklıkları arasında güçlü negatif bir korelasyon vardır ( $\mathrm{r}_{\text {gündüz }}=-0.664 ; \mathrm{p}<0.001, \quad \mathrm{r}_{\text {gece }}=-0.701$; $\mathrm{p}<0.001$ ). Oysa aynı grupta eğim ile ortalama gündüz-gece farkı arasında zayıf negatif bir korelasyon bulunmuştur $\left(\mathrm{r}_{\text {fark }}=-0.203\right.$; $\mathrm{p}<0.001$ ). Diğer taraftan, 46-90' lik eğim grubu için, eğim ile ortalama gündüz sıcaklıkları arasında kısmen zayıf negatif bir korelasyon vardır $\left(\mathrm{r}_{\text {gündüz }}=-0.288 ; \mathrm{p}<0.001\right)$. Oysa ayn1 grupta eğim ile ortalama gece sıcaklıkları arasında zayıf bir ilişki bulunmuşken $\left(\mathrm{r}_{\text {gece }}=-0.369 ; \mathrm{p}<0.001\right)$, ortalama gündüz-gece farkı arasında güçlü negatif bir korelasyon bulunmuştur ( $\mathrm{r}_{\text {fark }}=-$ $0.634 ; \mathrm{p}<0.001)$.

Kuzey bakılar için; her eğim grubundan gündüz ve gece ölçülen ortalama sıcaklıklar ile gündüz-gece farkı ortalamaları arasındaki çeşitlilik önemli bulunmuştur $\left(\mathrm{F}_{\text {gündüz }}=33.217 ; \mathrm{df}_{1}=8\right.$; $\mathrm{df}=710 ; \mathrm{p}<0.0001, \quad \mathrm{~F}_{\text {gece }}=48.180 ; \quad \mathrm{df}_{1}=8 ; \mathrm{df}=710 ; \mathrm{p}<0.0001$, $\left.\mathrm{F}_{\text {fark }}=25.633 ; \mathrm{df}_{1}=8 ; \mathrm{df}=710 ; \mathrm{p}<0.0001\right)$. Aynı zamanda gündüz ve gece $0-45^{0}$ 'lik eğim grubundan ölçülen değerler ile $46-90^{\circ}$ lik eğim grubundan ölçülen değerler arasındaki fark anlamlı bulunmuştur ( $\mathrm{t}_{\text {gündüz }}=19.665 ; \mathrm{df}=405 ; \mathrm{p}<0.0001, \mathrm{t}_{\text {gece }}=18,001$; $\left.\mathrm{df}=405 ; \mathrm{p}<0.0001, \mathrm{t}_{\text {fark }}=16.722 ; \mathrm{df}=405 ; \mathrm{p}<0.0001\right)$.

Son olarak, güney ve kuzey bakılarından gündüz ve gece ölçülen ortalama sıcaklıklar ile gündüz-gece farkı ortalamaları arasındaki farklar istatistiksel olarak anlamlıdır $\left(\mathrm{t}_{\text {gündüz }}=33.112\right.$; $\mathrm{df}=405 ; \mathrm{p}<0.0001, \mathrm{t}_{\text {gece }}=38.415 ; \mathrm{df}=405 ; \mathrm{p}<0.0001, \mathrm{t}_{\text {fark }}=30.588$; $\mathrm{df}=405 ; \mathrm{p}<0.0001)$. Yani kuzey bakılardaki sıcaklık değişimleri, güney yönlü bakılardakine oranla çok daha yüksektir. Ayrıca, kuzey bakılar, güney bakılara oranla çok daha soğuktur.

Türün habitlarındaki davranışları değerlendirildiğinde; eşeylere göre bireylerin ölü ve canlı olarak yakalanma frekansları bakımından cinsiyetler arasında istatistiksel farklılık bulunmuştur. Ancak bu durumdan kesinlikle populasyondaki erkek bireylerin daha yoğun oldukları anlamı çıkarılmamalıdır. Buradan elde edilecek sonuç erkek bireyler dişi bireylere oranla daha çok hareketli olup ve daha sık dişarıya çıkmaktadırlar. Bu nedenle erkekler dişilere oranlar daha çok risk altındadırlar. Buna benzer bulgular Yavuz ve ark., (2011a) tarafından yapılan çalışmada $M$. levis türü için tespit edilmiş olup, erkek bireylerin hareletlilik ve risk oranları yüksektir. Oysa Yavuz ve ark., (2010, 2011b) ve Yavuz ve Tunç (2016) tarafından yapılan diğer çalışmalarda; . guentheri ve $M$. anatolicus türleri için eşeyler arasında bir farklılık bulunamamıştır. Dolayısıyla $M$. subterraneus'tan farklı olarak bu pouplasyonlardaki eşeyler arasındaki hareketlilik ve risk oranı benzer gözükmektedir.

Habitat yapısı olarak ele alındığında Microtus cinsinin en yakın akrabalarından olan Chionomys cinsi üyelerinin daha çok kayalıklar arasındaki açık alanlarda yaşamayı tercih etmekte olduğu (Ognev, 1964; Sidlovskij, 1976; Kratochvil, 1981 ve 1983; Krapp, 1982; Kryštufek ve Kovačić, 1989), nadiren de olsa orman içinde nemli biyotoplarda yaşadıkları söylenebilir. Genellikle verimsiz ve kurakçıl alanları tercih etmektedirler. $M$. subterraneus türü de büyük çoğunlukla bu tip biyotopları tercih etmektedir. Dolayısıyla bu tip biyotoplarda sympatrik olarak bulunma olasılıkları daha yüksektir. Diğer taraftan, doğrudan orman içinde ve orman sınırındaki biyotoplarda yaşadıkları görülmemiştir.

Türün tercih ettiği habitatların eğimi incelendiğinde; ölü ve canlı yakalanma frekanslarının $31-60^{\circ}$ 'lik eğimli alanlarda yüksek olduğu, hatta bu eğim aralığında populasyon yoğunluklarının da yüksek olduğu tespit edilmiştir. Bu durum 
Yavuz ve ark., (2010, 2011a) ve Yavuz ve Tunç (2016)'un $M$. guenteheri ve $M$. levis için yaptıkları çalışmalarda elde ettikleri bulgularla örtüşmektedir.

Bunun yanında türün güneş alan bakılardaki habitat ve biyotoplarda yuva yapmayı tercih etmesinin nedeni türün bir memeli hayvan olmasina ve memelilerinde homoitermal canlılar olmalarına bağlanabilir. Vücut sıcaklıklarını sabit tutmak zorunda olan homoitermal hayvanların güneş alan ve eğimli yuva alanlarının çok çabuk ısınıp, geç soğumasınından kaynaklı olarak enerjetik bir avantajları ortaya çıkmakla birlikte, bu tip alanların tercihinde en önemli etmen olduğu söylenebilir (Yavuz ve ark., 2010). "Eğimli alanlarda toprak gün içinde güneşli peryot süresince güneş 1şınlarını ve enerjiyi absorbe eder" (Porter ve ark., 2002). "Bu nedenle eğimli alanlar düz alanlara göre daha hızlı ısınır ve geç soğurlar. Toprak gece boyunca absorbe ettiği ısıyı yavaş yavaş bırakır. Sonuçta, eğimli alanlarda ortalama gündüz-gece sicaklık farkı çok yüksek değildir" (Yavuz ve ark., 2010). "Bu durumda güney bakılı eğimli alanların yuva alanı olarak seçilmesi, vücut sıcaklığını sabit tutmak zorunda olan bir canlı için beklenen bir durumdur" (Yavuz ve ark., 2011a). Bu savlar bu türün tercihleri içinde geçerli görünmektedir.

\section{Teşekkür}

"Bu çalışma Akdeniz Üniversitesi Bilimsel Araştırma Projeleri Yönetim Birimi (BAP) tarafından 2009.01.0105.005 proje numarası ile desteklenmiştir" (Hayvan Deneyleri Yerel Etik Kurulu İzin, 08.01.2009 Tarih, Toplantı No:1, Karar No:06).

\section{Kaynakça}

Çolak, E., Yiğit, N., Sözen, M., Özkurt, S., (1998). A study on taxonomic status of Microtus subterraneus (de Selys Longchamps, 1836) and Microtus majori Thomas, 1906 (Mammalia: Rodentia) in Turkey. Turk. J. Zool. 22, 119-129.

Krapp, F., (1982). Microtus nivalis (Martins, 1842) Schneemaus. In: Niethammer, J. \& Krapp, F. (eds.) Handbuch der Saugetiere Europas. Bd. 2/I. Rodentia II (Cricetidae, Arvicolidae, Zapodidae, Spalacidae, Hystricidae, Capromyidae). Akademische Verlagsgesellschaft, Wiesbaden, 261-283.

Kratochvil, J., (1981). Chionomys nivalis (Arvicolidae, Rodentia). Acta Sc. Nat. Brno. 15(11): 1-62.

Kratochvil, J., (1983). Microtus arvalis und M. epiroticus in der Bulgarischen Volksrepublik. Folia Zoologica 32: 193-202.

Krebs, C. J. (1999). Ecological Methodology, 2nd ed., Addison-Welsey Educational Publishers, Inc., Menlo Park, CA. $620 \mathrm{pp}$.

Kryštufek B, Kovačić D., (1989) Vertical distribution of the snow vole Microtus nivalis (Martins, 1842) in northwestern Yugoslavia. Z. Saugetierkunde 54: 153-156.

Kryštufek B., Vohralik V., (2005) Mammals of Turkey and Cyprus. Rodentia I: Sciuridae, Dipodidae, Gliridae, Arvicolinae. Koper, 1-292.

Ognev, S.I., (1964). Mammals of the U.S.S.R. and adjacent countries. Mammals of Eastern Europe and northern Asia. Vol. VII, Rodents. Israel Program for Scientific Translations, Jerusalem, 4:1-425.

Pollock, K.H., Nichols JD, Brownie C, Hines JE. (1990). Statistical inference for capture-recapture experiments. Wildlife Monographs, 107: 1-97.
Tüm bu bulgular birlikte değerlendirildiğinde, $M$. subterraneus türü 31-60' 'lik eğimli, verimsiz-kurakçıl alanlar ve bu alanlara komşu karışık ve açık, güneş alan bakılarda yer alan habitatları tercih etmektedir.

\section{Sonuç}

Türün genel olarak bilinen habitatlarının (kurak ve verimsiz habitatlar) yakınındaki komşu alanlarda da bulunabilmesi bu tip alanlarda yapılan tarım ve silvikültürel faaliyetleri doğrudan etkileyebilecek bir potansiyeli içermektedir. Özellikle bu türün toprak altına yuvalar kazarak herbivor beslendiği, bitkilerin kök ve filizlerine zarar verebileceği düşünüldüğünde durumun önemi daha da ortaya çıkmaktadır. Bu durumda ileride yaşanabilecek olası problemlerde bu çalışmayla elde edilmiş ekolojik verilerin sorunların çözümünde önemli bir rol oynayabileceği düşünülebilir. İleride ortaya çıkabilecek sorunlarda özellikle 31$60^{\circ}$ 'lik eğimli alanların risk oranını arttırabileceği unutulmamalıdır.

Porter, W.P., Sabo, J.L., Tracy, C.R., Reichman, O.J. and Ramankutty, N., (2002). Physiology on a Landscape Scale: Plant-Animal Interactions, Integ. and Comp. Biol., 42: 431-453.

Šidlovskij, M.V., (1976). [Key to the rodents of Transcaucasia] Opredelitel'gryzunov Zakavkaz'ja / Akademija nauk Gruzinsko SSR Institut zoologii, Tbilisi (in Russian), 1255.

Yavuz, M., Öz, M., Albayrak, I., (2011a). Ecological Preferences of the East European Vole Microtus levis (Rodentia: Cricetidae) in the West Mediterranean Region at Eleven New Localities. Ekoloji, vol.20, 30-36.

Yavuz, M., Öz, M., Albayrak I., (2011b). Ecological Preferences of the Anatolian Vole Microtus anatolicus (Rodentia: Cricetidae), an endemic species of the Anatolia. Ekoloji, vol.20, 59-65.

Yavuz, M., Öz, M., Albayrak, İ., (2010). Levant vole Microtus guentheri (Danford and Alston 1880) prefers southerlyfacing slopes in agricultural sites at Antalya, Turkey. NorthWestern Journal Of Zoology, vol.6, 36-46.

Yavuz, M., Tunç, M.R., (2016). Levant Voles (Microtus guentheri (Danford And Alston 1880)) Prefer Southerlyfacing Slopes In Agricultural Sites At Hatay, Turkey. Fresenius Environmental Bulletin, vol.25, 2531-2538. 